\title{
Morphological and molecular characterisation of Heliconema hainanensis sp. nov. (Spirurina: Physalopteridae) from congers in the South China Sea, with a key to the species of Heliconema
}

\author{
Liang Li/+, Yuan-Yuan Liu', Bao-Chen Liu², Lu-Ping Zhang1 \\ ${ }^{1}$ College of Life Science, Hebei Normal University, Hebei Province, PR China ${ }^{2}$ Botou Vocational College, Botou, Hebei Province, PR China
}

Heliconema hainanensis sp. nov. collected from Uroconger lepturus (Richardson) (Anguilliformes: Congridae), Muraenesox cinereus (Forsskål) and Congresox talabonoides (Bleeker) (Anguilliformes: Muraenesocidae) in the South China Sea was described using light and scanning electron microscopy. The new species differs from its congeners by the following morphology: pseudolabia, the number and arrangement of caudal papillae (4 pairs of pedunculate precloacal papillae arranged in 2 groups of 2 and 2 pairs and 6 pairs of pedunculate postcloacal papillae arranged in 4 groups of 1, 2, 1 and 2 pairs), the length of spicules [left spicule 0.51-0.69 mm, right spicule 0.20-0.27 $\mathrm{mm}$, spicule (right:left) ratio 1:2.20-2.69] and the morphology of the female tail tip. In addition, specimens of the new species collected from the three different hosts and specimens of an unidentified species of Heliconema collected from U. lepturus were characterised using molecular methods by sequencing the internal transcribed spacer (ITS) of ribosomal DNA. Analyses and comparison of the ITS sequence of $\mathrm{H}$. hainanensis $s p$. nov. with Heliconema $s p$. support the validity of the new species based on morphological observations. An identification key to the species of Heliconema is also provided.

Key words: Proleptinae - Heliconema - molecular taxonomy - morphology - new species

Adult Heliconema nematodes commonly occur in the digestive tract of fishes of the orders Anguilliformes and Synbranchiformes (Li 1934, Ogden 1969, Gupta \& Duggal 1989, Crites \& Overstreet 1991, Moravec et al. 2007), but some species can also parasitise snakes (Ortlepp 1923, Fusco \& Palmieri 1980). Travassos (1919) erected the genus Heliconema and designated Heliconema heliconema Travassos 1919 from the chain moray Echidna catenata (Bloch) (Anguilliformes: Muraenidae) as the type species. Until 2012, there were only nine recognisable species in Heliconema worldwide, including H. heliconema Travassos 1919, Heliconema longissimum (Ortlepp 1923), Heliconema brevispiculum Baylis 1934, Heliconema baylisi Ogden 1969, Heliconema serpens Fusco and Palmieri 1980, Heliconema psammobatidus Threlfall and Carvajal 1984, Heliconema kherai Gupta and Duggal 1989, Heliconema brooksi Crites and Overstreet 1991 and Heliconema savala Akram 1996 (Travassos 1919, Ortlepp 1923, Baylis 1934, Li 1934, Ogden 1969, Fusco \& Palmieri 1980, Threlfall \& Carvajal 1984, Gupta \& Duggal 1989, Crites \& Overstreet 1991, Akram 1996, Moravec et

Financial support: National Natural Science Foundation of China (31101615, 30970318), the Natural Science Foundation of Hebei Province (C2012205007), the China Postdoctoral Science Foundation (2012M520593), the Natural Science Foundation of Hebei Education Department (42012012), the Postdoctoral Programme of Hebei Normal University, the Science Foundation of Hebei Normal University (L2010B13)

+ Corresponding author: liangliangex369@126.com

Received 31 May 2012

Accepted 18 July 2012 al. 2007). Of these, only three species have been reported in China: H. longissimum from Anguilla japonica Temminck \& Schlegel (Anguilliformes: Anguillidae) and $H$. heliconema and $H$. brevispiculum from Muraenesox cinereus (Forsskål) (Anguilliformes: Muraenesocidae) (Li 1934, Wang et al. 1976, 1977, Pan et al. 1990). During a helminthological survey of marine fishes in the South China Sea from November 2009-December 2010, large numbers of spirurine nematodes identified morphologically as a new species. Heliconema hainanensis sp. nov. were collected from the intestine and stomach of the congers Uroconger lepturus (Richardson) (Anguilliformes: Congridae), M. cinereus (Forsskål) and Congresox talabonoides (Bleeker) (Anguilliformes: Muraenesocidae).

In recent years, morphological features combined with genetic information, such as sequences of the internal transcribed spacer (ITS) of nuclear ribosomal DNA (rDNA) and mitochondrial cytochrome C oxidase subunit I and II, have been successfully used for the accurate identification of nematodes at the species level for eggs, larvae and adults (Ivanova et al. 2007, Koubková et al. 2008, Mattiucci et al. 2008, Mašová et al. 2010, Guerrero et al. 2011, Li et al. 2012a, b, Testini et al. 2011). Consequently, specimens of this new species collected from three different hosts and specimens of Heliconema sp. collected from $U$. lepturus were characterised using molecular methods by sequencing and analysing the ITS region of rDNA to validate their taxonomic status. The present study is the first use of ITS-region sequencing for the purpose of species discrimination and identification in the genus Heliconema and represents a substantial step toward using sequence variation for species delimitation in this poorly characterised group. An identification key to the species of Heliconema is also provided. 


\section{MATERIALS AND METHODS}

Light and scanning electron microscopy (SEM) Fishes collected from the South China Sea were examined for parasites. Nematodes recovered from the digestive tract of various fishes were washed in physiological saline and then fixed and stored in $70 \%$ ethanol until use. For light microscopy studies, nematodes were clarified in lactophenol. Drawings were rendered with the aid of a Nikon microscope drawing attachment. For SEM, a portion of the specimens was selected for fixation in $4 \%$ formaldehyde solution, post-fixed in $1 \% \mathrm{OsO}_{4}$, dehydrated via an ethanol series and acetone, then critical-point dried. The specimens were coated with gold and examined on a Hitachi S-570 scanning electron microscope at an accelerating voltage of $15 \mathrm{kV}$.

Measurements (the range, followed by the mean in parentheses) are given in micrometres unless otherwise stated. Type specimens are deposited at the College of Life Sciences, Hebei Normal University (HBNU), Hebei Province, China. The collection data for the specimens of $H$. hainanensis sp. nov. are presented in Table.

Molecular procedures - Twenty-one nematodes (i.e., 6 randomly selected paratypes of $H$. hainanensis sp. nov. from each of the host species, $U$. lepturus, $M$. cinereus and $C$. talabonoides and 3 specimens of Heliconema sp. from $U$. lepturus) were subjected to molecular analysis. Genomic DNA from individual worms was extracted with the Column Genomic DNA Isolation Kit (Shanghai Sangon, China) according to the manufacturer's instructions. DNA was eluted in elution buffer and stored at $-20^{\circ} \mathrm{C}$ until use. The ITS region was amplified by polymerase chain reaction (PCR) using the primers NC5 (forward: 5'-GTAGGTGAACCTGCGGAAGGATCATT-3') and NC2 (reverse: 5'-TTAGTTTCTTCCTCCGCT-3') (Zhu et al. 1998). PCR was performed in $50 \mu \mathrm{L}$ of $\mathrm{PCR}$ reaction buffer containing $10 \mathrm{mM}$ Tris $\mathrm{HCl}, \mathrm{pH} 8.4,50 \mathrm{mM}$ $\mathrm{KCl}, 3.0 \mathrm{mM} \mathrm{MgCl}, 250 \mu \mathrm{M}$ of each deoxynucleotide triphosphate, $50 \mathrm{pmol}$ of each primer and $1.5 \mathrm{U}$ of Taq polymerase (Takara) in a thermocycler (2720, Applied Biosystems) using the following conditions: $94^{\circ} \mathrm{C}$ for 5 min (initial denaturation), followed by 30 cycles of $94^{\circ} \mathrm{C}$ for $30 \mathrm{~s}$ (denaturation), $55^{\circ} \mathrm{C}$ for $30 \mathrm{~s}$ (annealing), $72^{\circ} \mathrm{C}$ for
$70 \mathrm{~s}$ (extension) and a final extension at $72^{\circ} \mathrm{C}$ for $7 \mathrm{~min}$. PCR products were verified on a GoldView-stained 1.5\% agarose gel and purified with the Column PCR Product Purification Kit (Shanghai Sangon, China). Sequencing was performed using the DyeDeoxy Terminator Cycle Sequencing Kit (v.2, Applied Biosystems, California, USA) and an automated sequencer (ABI-PRISM 377). Sequencing for each sample was performed for both strands. Sequences were aligned using CLUSTALW2 (Thompson et al. 1994) and adjusted manually. The ITS sequences obtained were compared with those available in the National Center for Biotechnology Information (NCBI) database (ncbi.nlm.nih.gov) using the BLASTn algorithm.

\section{RESULTS}

\section{H. hainanensis sp. nov.}

(Figs 1-4)

The morphometrics of specimens collected from the three different hosts, U. lepturus, $M$. cinereus and $C$. talabonoides, were strikingly similar (i.e., no notable morphological variations were detected between specimens from different hosts).

Diagnosis - Medium-sized, whitish nematodes. Cuticle with fine transverse striations. Cephalic end rounded. Cuticle in cephalic region inflated to form a cephalic vesicle extending posteriorly to the level of deirids (Fig. 1A). Oral aperture dorsoventrally elongated, surrounded by two lateral pseudolabia (Figs 1C, 2A, 3A); each pseudolabium bears two large submedian (dorsolateral and ventrolateral) cephalic papillae and one small amphid situated at the base of the pseudolabium (Figs 1C, 2A, 3A); inner surface of each pseudolabium with a large median conical tooth and ridged subdorsal and subventral teeth (Figs 3B, 4A); any series of denticles absent. Buccal cavity short. Oesophagus divided into a short, narrow anterior muscular portion and a significantly longer, wide glandular portion. Nerve ring encircles the muscular oesophagus posterior to its middle (Fig. 1A, B). Small simple deirids situated at the level of the nerve ring (Figs 1A, 3C). Excretory pore situated slightly posterior to the anterior end of the glandular oesophagus (Fig. 1B). Posterior end of the body sexual dimorphism (Figs 2C, 3D).

TABLE

Specimens of Heliconema hainanensis sp. nov. collected from the South China Sea

\begin{tabular}{lccc}
\hline Hosts & Date of collection & Locality of collection & Prevalence and intensity (mean) \\
\hline Uroconger lepturus & $\begin{array}{c}\text { 24-30 November 2010 } \\
\text { 24-25 November 2010 }\end{array}$ & $\begin{array}{c}\text { Off Sanya, Hainan Island } \\
\text { Off Sanya, Hainan Island }\end{array}$ & $\begin{array}{c}2 / 11,42-126(84.0) \\
1 / 2,30(15.0)\end{array}$ \\
Muraenesox cinereus & 25-26 November 2009 & Off Beihai, Guangxi Province & $6 / 6,25-100(66.2)$ \\
& 1 December 2010 & Off Sanya, Hainan Island & $1 / 2,90$ \\
Congresox talabonoides & 26 November 2009 & Off Beihai, Guangxi Province & $2 / 2,3-84(43.5)$ \\
& 29 April 2010 & Off Zhanjiang, Guangdong Province & $1 / 1,54$
\end{tabular}


Male (24 specimens) - Body 17.3-23.8 (20.5) mm long; maximum width 274-392 (337). Pseudolabia 29-39 (35.0) long, 118-127 (122) wide. Cephalic vesicle 127-343 (204) long, 20-29 (22.9) wide. Entire oesophagus 1.96-2.74 (2.37) $\mathrm{mm}$ long, representing 10.4-13.4 (11.7)\% of body length; muscular oesophagus 245-363 (312) long, 78-108 (90.9) maximum width; glandular oesophagus 1.72-2.38 (2.06) $\mathrm{mm}$ long, 147-196 (162) maximum width; length ratio of two parts of the oesophagus 1:5.71-8.00 (1:6.66). Oesophageal-intestinal valve 49-98 (75.6) long, 118-157 (141) wide. Nerve ring, deirids and excretory pore 167-343 (253), 186-372 (289) and 235-441 (376), respectively, from the anterior extremity. Spicules dissimilar in shape, unequal in length; left spicule relatively long, 510-686 (574) in length, arcuate, narrow, tapering to fine point distally, representing 2.26-3.25 (2.83)\% of body length; right spicule short, 196-265 (238) long, thicker than left spicule, with distal end recurved, representing 1.01-1.40 (1.17)\% of body length; spicule (right:left) ratio 1:2.20-2.69 (1:2.42) (Fig. 1E, G). Gubernaculum absent. Posterior end of body spirally coiled ventrally (Fig. 2C). Caudal alae slightly expanded, supported by four twin pairs of subventral pedunculate precloacal papillae and six pairs of subventral pedunculate postcloacal papillae arranged in four groups of one, two, one and two pairs (Figs 1E, F, 2D). Each caudal papilla surrounded by a ring consisting of numerous small cuticular, papilla-like protuberances (in young males, caudal papilla as knob-like projection without sur-
A

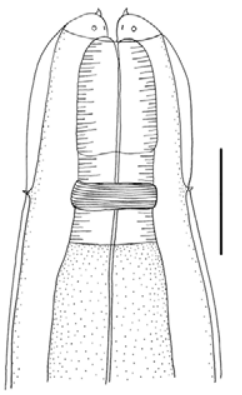

E

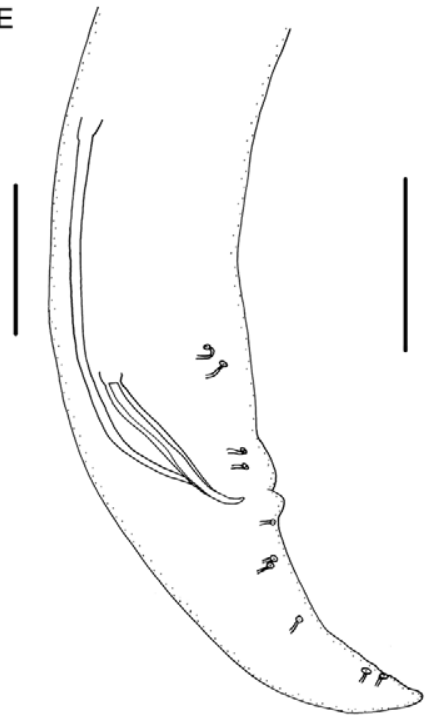

$\mathrm{H}$

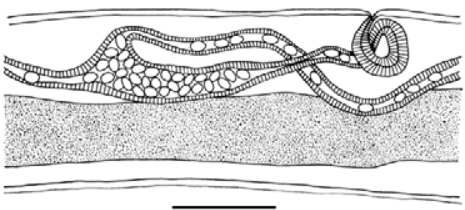

$\mathrm{F}$
B

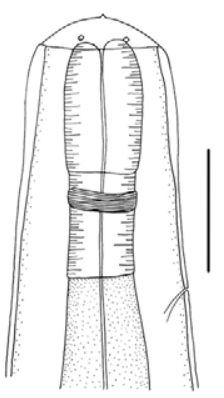

C

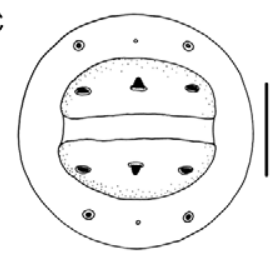

$\mathrm{D}$
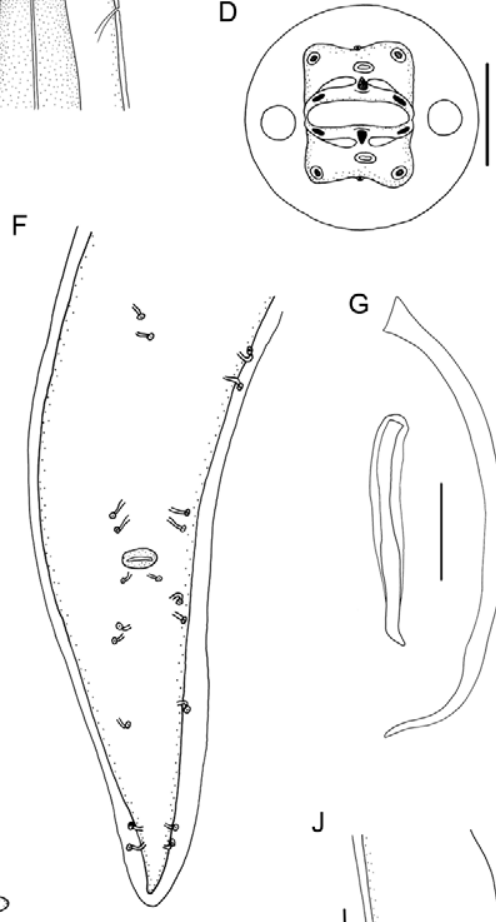

I

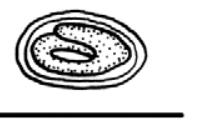

G

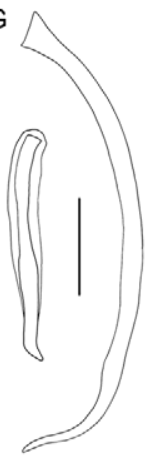

$\mathrm{J}$

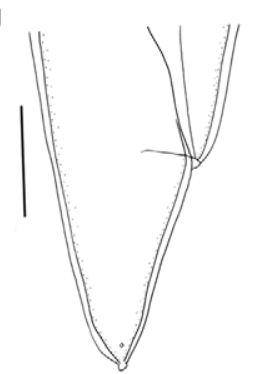

Fig. 1: Heliconema hainanensis sp. nov. from Uroconger lepturus (Richardson) in the South China Sea (A-C, E-J). A: anterior part of female, lateral view; B: anterior part of female, ventral view; C: cephalic end of male (reconstructed from scanning electron microscopy, apical view; D: cephalic end of Heliconema longissimum (Ortlepp), apical view [(redrawn after Moravec et al. (2007)]; E: posterior end of male (showing spicules and caudal papillae), lateral view; F: posterior end of male (showing caudal papillae and caudal alae), ventral view; G: spicules; H: region of vulva; I: larvated egg; J: posterior end of female, lateral view. Bars: A, B, E, F, H, J: $200 \mu \mathrm{m}$; C: $40 \mu \mathrm{m}$; D: $30 \mu \mathrm{m}$; G: $100 \mu \mathrm{m}$; I: $50 \mu \mathrm{m}$. 
rounding cuticular, papilla-like protuberances) (Figs 2E, F, 4B-D). Ventral precloacal surface forming 20 or more rows of tessellated longitudinal ridges (Fig. $2 \mathrm{H}$ ) (in young males, tessellated longitudinal ridges weak, ridges lack clear demarcations) (Fig. 2G). Tail 294-412 (364) long with rounded tip (Figs 2B, 4C). Phasmids not observed.

Female (24 specimens) - Body 23.6-42.1 (35.3) mm long; maximum width 490-735 (622). Pseudolabia 29-49 (44.8) long, 127-147 (140) wide. Cephalic vesicle 196-294 (216) long, 29-39 (31.4) wide. Entire oesophagus 2.89-3.92 (3.38) $\mathrm{mm}$ long, representing 8.27-12.2 (10.4)\% of body length; muscular oesophagus 392-461 (425) long, 118-176 (147) maximum width; glandular oesophagus 2.50-3.47 (2.96) $\mathrm{mm}$ long, 176-265 (234) maximum width; length ratio of two parts of the oesophagus 1:6.23-7.76 (1:6.98). Oesophageal-intestinal valve 78-137 (103) long, 157-274
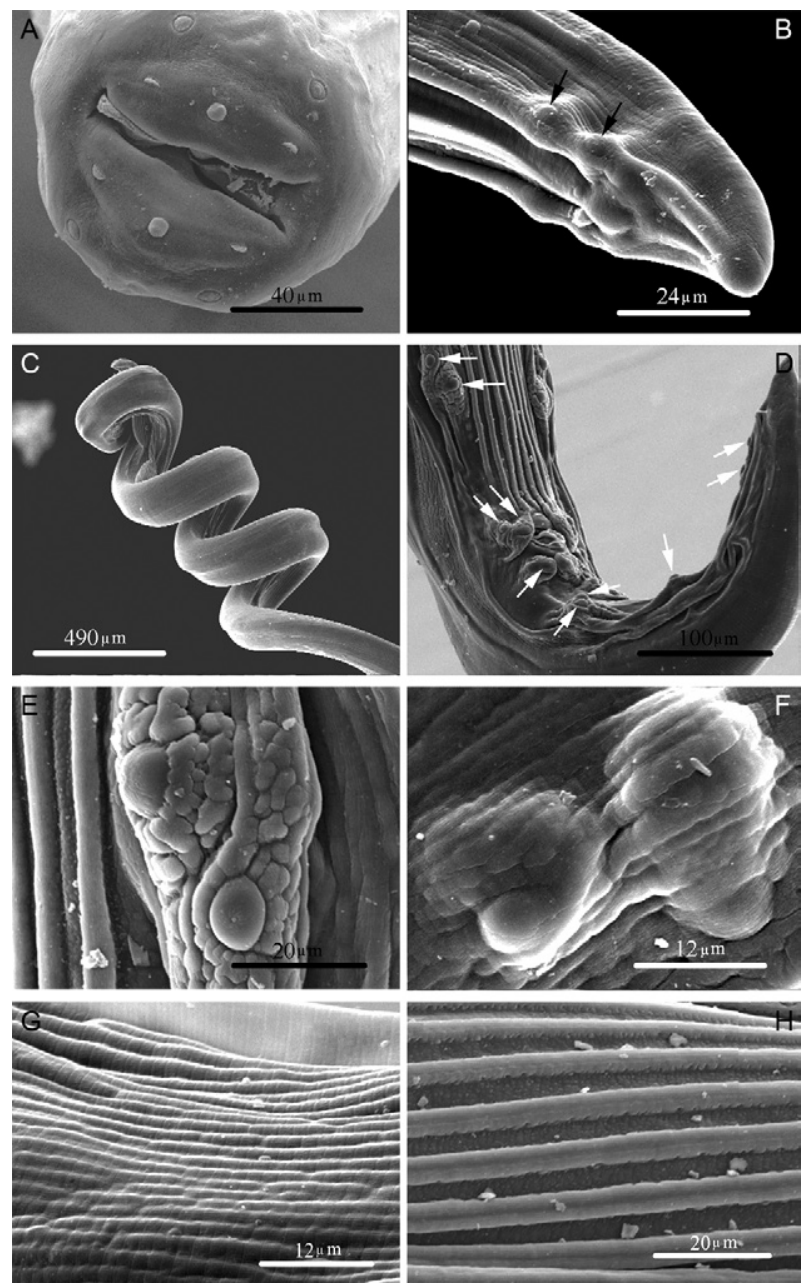

Fig. 2: scanning electron micrographs of Heliconema hainanensis sp. nov. from Uroconger lepturus (Richardson) in the South China Sea. A: cephalic extremity of mature male, apical view; B: apical portion of young male tail (last 2 postcloacal papillae arrowed), ventral view; $\mathrm{C}$ : posterior end of mature male, dorsal view; D: posterior end of mature male (caudal papillae arrowed), ventrolateral view; E: postcloacal papillae of mature male; F: postcloacal papillae of young male; G: precloacal tessellated longitudinal ridges of young male; $\mathrm{H}$ : precloacal tessellated longitudinal ridges of mature male.
(213) wide. Nerve ring, deirids and excretory pore 294363 (317), 343-372 (353) and 392-441 (415), respectively, from the anterior extremity. Rectum a hyaline tube. Vulva slit-like without a protruding flap (Figs 1H, 3E) situated $11.2-16.9$ (14.2) $\mathrm{mm}$ from anterior extremity at 35.4-47.4 (40.9)\% of the body length. Vagina narrow, muscular, initially directed anteriorly from the vulva and then oriented posteriorly (Fig. 1H). Uteri didelphic, amphidelphic, containing numerous oval, thick-shelled, embryonated (larvated) eggs. Eggs suboval to rounded, 39-49 (45.7) long, 20-39 (30.5) wide (Fig. 1I). Posterior end of body nearly straight, not spirally coiled ventrally (Fig. 3D). Tail 294412 (363) long with nipple-like tip. A pair of small lateral phasmids is present near tail tip (Figs 1J, 3F).

Type host - U. lepturus (Richardson) (Anguilliformes: Congridae).

Site of infection - Intestine and stomach.

Type locality - South China Sea, Off Sanya (109³0’E $\left.18^{\circ} 12^{\prime} \mathrm{N}\right)$, Hainan Island, China.

Type data and depository - Holotype: male from $U$. lepturus, South China Sea, Off Sanya (HBNU-F1135); allotype: female from U. lepturus, South China Sea, Off Sanya (HBNU-F1136); paratypes: 75 males, 91 females from U. lepturus (HBNU-F1137), 29 males, 61 females from C. talabonoides (HBNU-F1138), six males, 24 females from M. cinereus (HBNU-F1139), South China Sea, Off Sanya; 22 males, 65 females from $C$. talabonoides (HBNU-F1140), 172 males, 225 females from M. cinereus (HBNU-F1141), South China Sea, Off Beihai; 23 males, 31 females from C. talabonoides (HBNU-F1142), South China Sea, Off Zhanjiang.

Other material examined - M. cinereus (Forsskål) (Anguilliformes: Muraenesocidae) and C. talabonoides (Bleeker) (Anguilliformes: Muraenesocidae).

Distribution - South China Sea, Off Sanya (109³0'E $\left.18^{\circ} 12^{\prime} \mathrm{N}\right)$, Hainan Island, Off Beihai $\left(109^{\circ} 12^{\prime} \mathrm{E} 21^{\circ} 48^{\prime} \mathrm{N}\right)$, Guangxi Province, Off Zhanjiang (110 $\left.39^{\circ} \mathrm{E} 21^{\circ} 26^{\prime} \mathrm{N}\right)$, Guangdong Province, China.

\section{Host-parasite data - For details, see Table.}

Etymology - The species name refers to the name of the type locality, Hainan Island.

DNA characterisation - Ten sequence types were obtained for the ITS region of the partial rDNA in $\mathrm{H}$. hainanensis sp. nov. based on the specimens collected from the three different hosts examined here. The length of the ITS sequence of $H$. hainanensis sp. nov. ranged from 1,191-1,203 bp and showed low intraspecific nucleotide variability among the different sequence types (nucleotide differences from 0.16-1\%) (Supplementary data). In Heliconema sp., two sequence types were obtained for the ITS region and the length of the ITS varied between 1,349-1,354 bp. A pairwise comparison between the two sequence types of Heliconema sp. demonstrated 0.96\% nucleotide differences (Supplementary data). No ITS sequence from Heliconema is registered in GenBank; therefore, a pairwise comparison could only be performed between $H$. hainanensis sp. nov. and Helicone- 
ma sp. A high level of sequence variation was detected between the two species (greater than 50\% nucleotide differences) because of the large number of nucleotide insertions, deletions and substitutions present (Supplementary data). The ITS sequences of $H$. hainanensis sp. nov. and Heliconema sp. were deposited in the GenBank database (ncbi.nlm.nih.gov) under the following accessions: H. hainanensis sp. nov., JQ750474-JQ750483 and Heliconema sp., JQ750472 and JQ750473.

\section{DISCUSSION}

In the genus Heliconema, the new species described here is similar to the congeners $H$. longissimum, $H$. baylisi, $H$. serpens and $H$. kherai in that they exhibit a vulva that lacks a prominent protruding flap. H. hainanensis sp. nov. can be readily distinguished from $H$. serpens and $H$. kherai by having six pairs of pedunculate postcloacal papillae (vs. 4 pairs in the latter 2 species). The new species differs from $H$. baylisi by having distinctively unequal spicules (right:left spicule ratio of 1:2.20-2.69 in the former vs. 1:1.11-1.36 in the latter), a different arrangement of postcloacal papillae and a different morphology of the female tail tip. H. hainanensis sp. nov. differs from
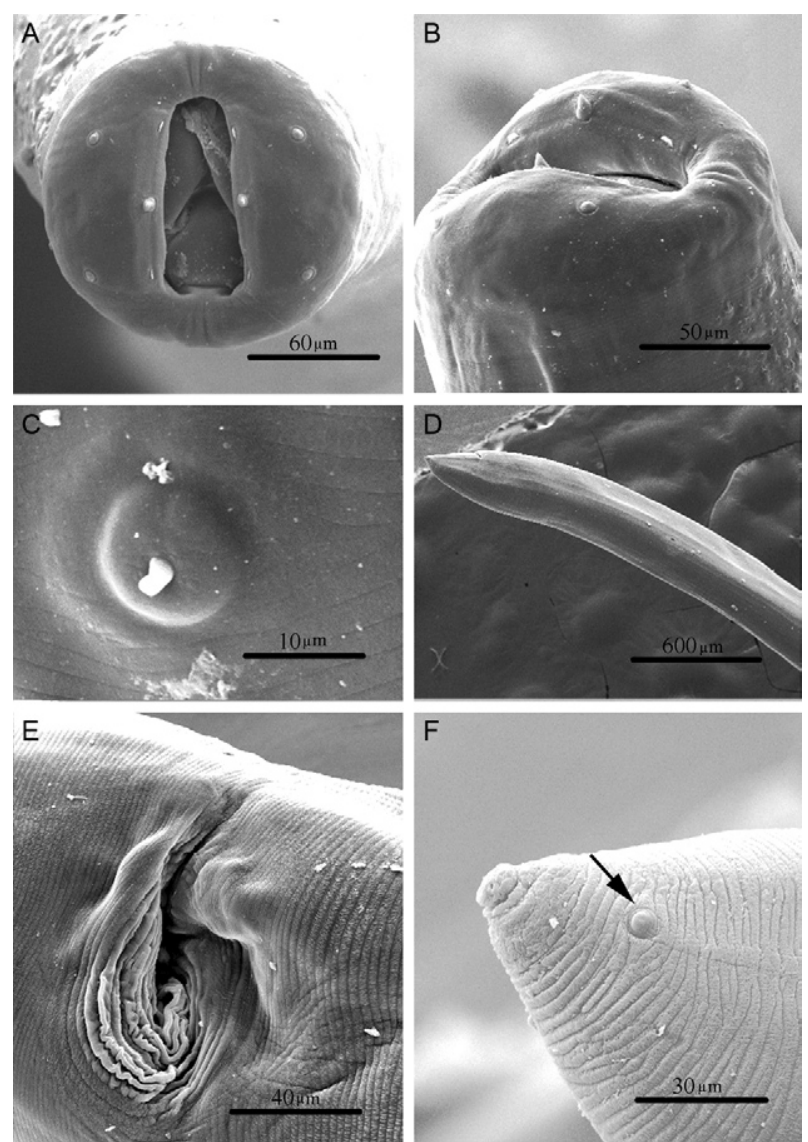

Fig. 3: scanning electron micrographs of Heliconema hainanensis sp. nov. from Uroconger lepturus (Richardson) in the South China Sea, female. A: cephalic extremity, apical view; B: cephalic extremity, lateral view; C: deirid; D: posterior end of body, lateral view; E: vulva; F: apical portion of tail (phasmid arrowed), lateral view.
H. longissimum by having a pseudolabium without depressions or grooves (Fig. 1C, D), a female tail with a nipple-like tip and a different number, morphology and arrangement of postcloacal papillae; all of the six pairs of postcloacal papillae are pedunculate in the former, whereas three of the seven pairs of postcloacal papillae are sessile in the latter. The Heliconema sp. material in the present study was also collected from the same host and locality (U. lepturus, Off Sanya, Hainan Island) as $H$. hainanensis sp. nov. We were unable to precisely identify the present material to the species level morphologically because only four female specimens were found in the digestive tract of $U$. lepturus. However, from $H$. hainanensis sp. nov., Heliconema sp. differs by having a significantly larger body size (body length 43.3-56.7 $\mathrm{mm}$ in Heliconema sp. vs. $23.6-42.1 \mathrm{~mm}$ in the new species in the female) and the female tail lacks a nipple-like tip.

According to the traditional diagnostic characters and keys to the Heliconema species provided by Fusco and Palmieri (1980), Gupta and Duggal (1989), Crites and Overstreet (1991) and Akram (1996), the number of ventral precloacal tessellated longitudinal ridges (area rugosa) is critical to discriminating species of Heliconema. However, based on observations in some spirurine nematodes, such as Rhabdochona spp, Moravec et al. (2007) determined that this feature might be unreliable and variable within a species of Heliconema because the number of such ridges depends in part on the body size and age of the worm. In our study, the precloacal tessellated longitudinal ridges in the young males of $H$. hainanensis sp. nov. were weak (ridges without clear demarcation) and difficult to observe by light microscopy.

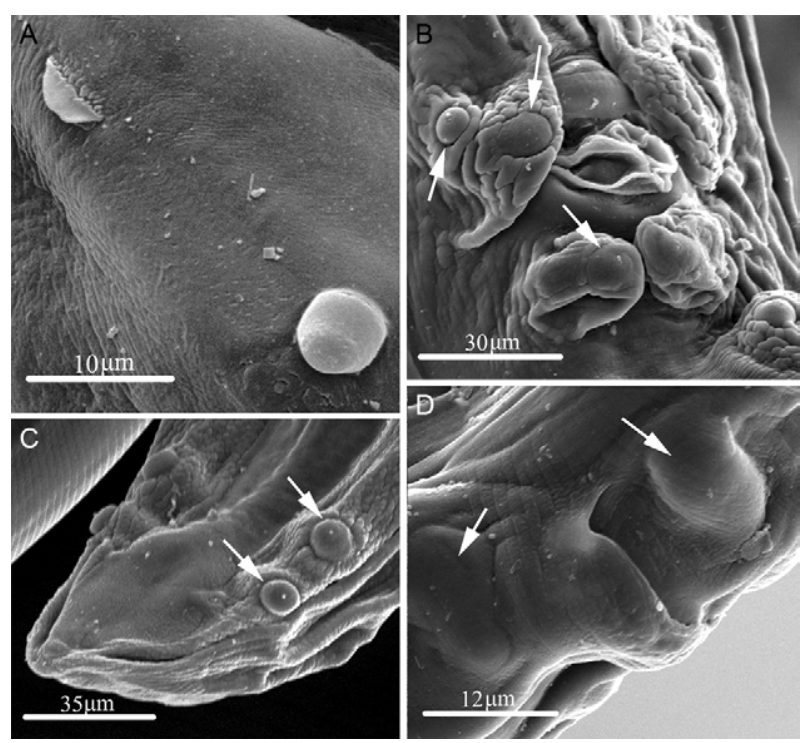

Fig. 4: scanning electron micrographs of Heliconema hainanensis sp. nov. from Uroconger lepturus (Richardson) in the South China Sea. A: large median conical tooth and ridged subdorsal tooth, apical view; $\mathrm{B}$ : cloacal region of mature male (precloacal and postcloacal papillae arrowed), ventral view; C: apical portion of mature male tail (last 2 postcloacal papillae arrowed), ventral view; D: cloacal region of young male (precloacal and postcloacal papillae arrowed), ventral view. 
This result agrees well with the opinion of Moravec et al. (2007) and this feature was discontinued from use in our identification key. In addition, the morphology of the caudal papillae varies markedly, depending mainly on the age of the worm. In mature males, the caudal papillae are mammiform and surrounded by a ring consisting of numerous small cuticular, papilla-like protuberances. However, in young males, caudal papillae only form as knob-like projections, without surrounding cuticular, papilla-like protuberances. This observation indicates that care must be taken in designating the age of specimens when differentiating species according to the morphology of caudal papillae.

The molecular analyses of the ITS sequence data obtained for $H$. hainanensis sp. nov. revealed 10 different sequence types based on the limited number of specimens collected from the three different hosts and exhibited a low level of sequence variation (nucleotide differences from $0.16-1 \%$ ), which is far lower than the interspecific sequence differences (greater than 50\% nucleotide difference between $H$. hainanensis sp. nov. and Heliconema sp.). Therefore, it is reasonable to consider the sequence differences in $H$. hainanensis sp. nov. as intraspecific nucleotide variations, similar to Heliconema sp. Moreover, the level of the intraspecific sequence differences in $H$. hainanensis sp. nov. do not appear to relate to any particular group of specimens, such as from different hosts or geographical locations. This result agrees with the morphological observations (i.e., no notable morphological variations were detected between specimens from different hosts or geographical locations) and confirms that all of the nematode material of the morphospecies $H$. hainanensis sp. nov. collected from the three different hosts represents a single species. The results from the present study demonstrate that utilising the ITS sequence of rDNA as a genetic marker is a powerful approach for the accurate identification and distinction of species of Heliconema.

\section{Key to species of the genus Heliconema}

1. Vulva with prominent protruding flap .................. 2

- Vulva without protruding flap .................................. 6

2. Spicule (right:left) ratio of 1:9.1-20.0 .................... 3

- Spicule (right:left) ratio of 1:2.4-4.3 ....................... 5

3. Paracloacal papillae absent, left spicule of 2.09$3.50 \mathrm{~mm}$....................................................... H. brooksi

- Paracloacal papillae one-two pairs, left spicule of 4.00-7.30 mm

4. Four pairs precloacal papillae, one pair paracloacal papillae; left spicule of $5.40-7.30 \mathrm{~mm}$, right spicule of $0.30-0.35 \mathrm{~mm}$; vulva at approximately the second quarter of the body H. heliconema

- Three pairs precloacal papillae, two pairs paracloacal papillae; left spicule of $4.00 \mathrm{~mm}$, right spicule of $0.27 \mathrm{~mm}$; vulva at approximately the first third of the body

5. Spicule (right:left) ratio averaging 1:2.4 H. brevispiculum

- Spicule (right:left) ratio of 1:4.1-4.3 H. psammobatidus

6. Postcloacal papillae five-seven pairs

- Postcloacal papillae four pairs
7. Pseudolabium with oval lateroterminal depression (Fig. 1D), postcloacal papillae seven pairs

H. longissimum

- Pseudolabium without oval lateroterminal depression (Fig. 1C), postcloacal papillae five-six pairs ......... 8

8. Spicule distinctively unequal (right:left) ratio of 1:2.20-2.69 (averaging 1:2.42); tail of female with a nipple-like tip H. hainanensis sp. nov.

- Spicule subequal (right:left) ratio of 1:1.11-1.36 (averaging 1:1.21); tail of female is rounded, without a nipple-like tip H. baylisi

9. Spicule (right:left) ratio averaging 1:1.7 collected from water snake H. serpens

- Spicule (right:left) ratio averaging 1:2.1 collected from freshwater fish H. kherai

\section{ACKNOWLEDGEMENTS}

To Associate Professor Rui-Yong An (College of Life Science, HBNU), for identifying the fishes, and to Dr David I Gibson (Department of Zoology, Natural History Museum, London, UK), for sending us some literature on Heliconema.

\section{REFERENCES}

Akram M 1996. Heliconema savala n. sp. (Nematoda: Physalopteridae) from marine fish Lepturacanthus savala (Cuvier) (Trichiuridae) and Psettodes erumei (Schneider) new host (Pisces: Psettodidae) of physalopterid nematode, Bulbocephalus inglisi Rasheed, 1966 in Pakistan. Pak J Mar Sci 5: 137-143.

Baylis HA 1934. Some spirurid nematodes from Queensland. Ann Mag Nat His 14: 142-153.

Crites JL, Overstreet RM 1991. Heliconema brooksi n. sp. (Nematoda: Physalopteridae) from the ophichthid eel Ophichthus gomesi in the Gulf of Mexico. J Parasitol 77: 42-50.

Fusco AC, Palmieri JR 1980. Heliconema serpens sp. n. (Nematoda: Physalopteridae) and Camallanides malayensis sp. n. (Nematoda: Camallanidae) from Cerberus rhynchops (Schneider) (Reptilia: Colubridae) in Malaysia. Proc Helminthol Soc Wash 47: 72-79.

Guerrero R, Bain O, Martin C, Barbuto M 2011. A new species of Litomosoides (Nematoda: Onchocercidae), parasite of Nectomys palmipes (Rodentia: Cricetidae: Sigmodontinae) from Venezuela: description, molecular evidence, Wolbachia pipientis screening. Folia Parasitol 58: 149-156.

Gupta NK, Duggal CL 1989. On a new species of genus Heliconema (Nematoda: Physalopteridae) from a freshwater fish, with a key to the species of the genus. Res Bull Panjab Univ (Sci) 40: 73-75.

Ivanova E, Spiridonov S, Bain O 2007. Ocular oxyspirurosis of primates in zoos: intermediate host, worm morphology and probable origin of the infection in the Moscow Zoo. Parasite 14: 287-298.

Koubková B, Baruš V, Hodová I, Šimková A 2008. Morphometric and molecular characteristics of Labeonema synodontisi n. comb. (Nematoda: Atractidae) from the West African fishes. Parasitol Res 102: 1013-1020.

Li HC 1934. Report on a collection of parasitic nematodes, mainly from North China. Part 2. Spiruroidea. Trans Am Microsc Soc 53: 174-195.

Li L, Gibson DI, Liu YY, Zhang LP 2012a. Morphological and molecular study of the poorly known species Pseudanisakis rajae (Yamaguti, 1941) (Nematoda: Acanthocheilidae) from elasmobranchs in the Yellow Sea and Taiwan Strait off the coast of China. Syst Parasitol 81: 115-123.

Li L, Liu YY, Liu BC, Zhang LP 2012b. Morphological and molecular evidence for a new species of the genus Raphidascaris (Nema- 
toda: Anisakidae) from marine fishes from the South China Sea. Parasitol Res 110: 1473-1479.

Mašová Š, Moravec F, Baruš V, Seifertová M 2010. Redescription, systematic status and molecular characterization of Multicaecum heterotis Petter, Vassiliadès et Marchand, 1979 (Nematoda: Heterocheilidae), an intestinal parasite of Heterotis niloticus (Osteichthyes: Arapaimidae) in Africa. Folia Parasitol 57: 280-288.

Mattiucci S, Paoletti M, Olivero-Verbel J, Baldiris R, Arroyo-Salgado B, Garbin L, Navone G, Nascetti G 2008. Contracaecum bioccai n. sp. from the brown pelican Pelecanus occidentalis (L.) in Colombia (Nematoda: Anisakidae): morphology, molecular evidence and its genetic relationship with congeners from fisheating birds. Syst Parasitol 69: 101-121.

Moravec F, Taraschewski H, Anantaphruti MT, Maipanich W, Laoprasert T 2007. Heliconema longissimum (Ortlepp, 1923) (Nematoda: Physalopteridae) from Pisodonophis boro (Teleostei: Ophichthidae) in Thailand, with remarks on the taxonomy of the Proleptinae Schulz, 1927. Syst Parasitol 66: 73-80.

Ogden CG 1969. A revision of the genus Heliconema Travassos, 1919, Physalopteridae (Nematoda). J Nat Hist 3: 423-431.

Ortlepp RJ 1923. The nematode genus Physaloptera Rud. Proc Zool Soc London 1923: 999-1107.

Pan JH, Zhang JY, Li CM 1990. Fish parasitology, Science Press, Beijing, p. 443 pp.
Testini G, Papini R, Lia RP, Parisi A, Dantas-Torres F, Traversa D, Otranto D 2011. New insights into the morphology, molecular characterization and identification of Baylisascaris transfuga (Ascaridida, Ascarididae). Vet Parasitol 175: 97-102.

Thompson JD, Higgins DG, Gibson TJ 1994. CLUSTALW: improving the sensitivity of progressive multiple sequence alignment through sequence weighting, position-specific gap penalties and weight matrix choice. Nucleic Acids Res 22: 4673-4680.

Threlfall W, Carvajal J 1984. Heliconema psammobatidus sp. $\mathrm{n}$. (Nematoda: Physalopteridae) from a skate, Psammobatis lima (Chondrichthyes: Rajidae), taken in Chile. Proc Helminthol Soc Wash 51: 208-211.

Travassos L 1919. Informações sobre o material helminthológico colleccionado na Ilha da Trindade em 1916. Arch Mus Nac (Rio de J) 22: 161-167.

Wang PQ, Zhao YR, Tang RG 1976. A survey of the parasites of eels from Fujian Province, China, I. J Fujian Teach Univ (Nat Sci) 1976: 103-107.

Wang PQ, Zhao YR, Tang RG 1977. A survey of the parasites of eels from Fujian Province, China, II. J Fujian Teach Univ (Nat Sci) 1977: 78-92.

Zhu XQ, Gasser RB, Podolska M, Chilton N 1998. Characterization of anisakid nematodes with zoonotic potential by nuclear ribosomal DNA sequences. Int J Parasitol 28: 1911-1921. 


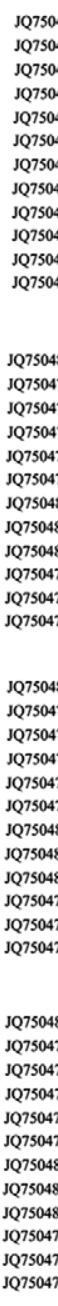

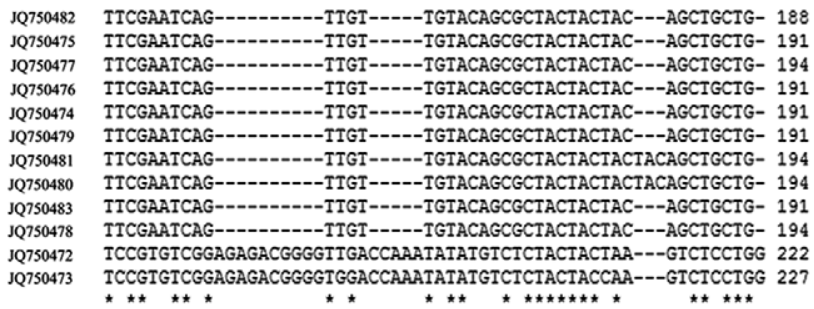

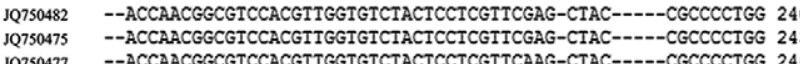

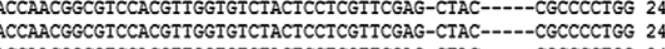

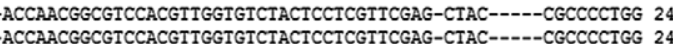

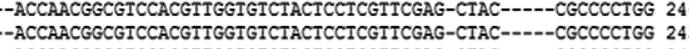

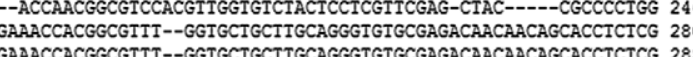

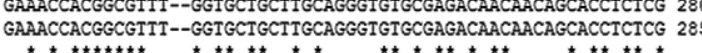

CCGTCGGTAGTGATGAGTGACGAGGCTCGA-GCGGCTCCTITTCCGGCAACACCAACCCC 29

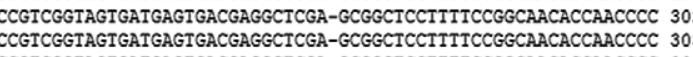

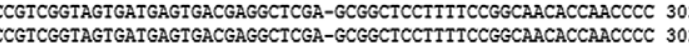

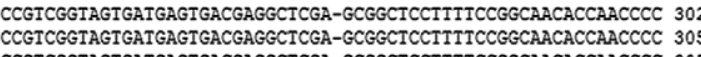

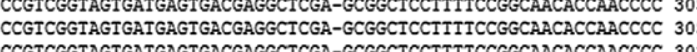

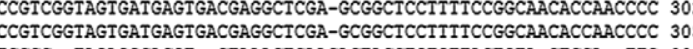

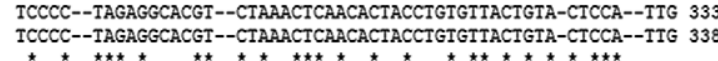

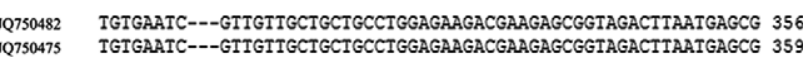

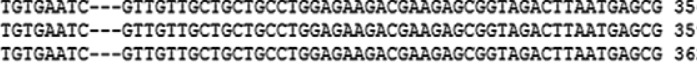

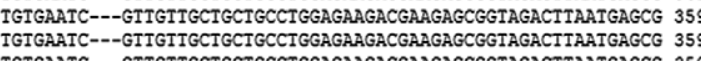

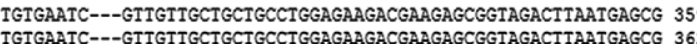

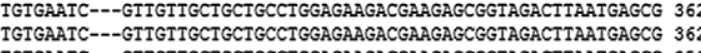

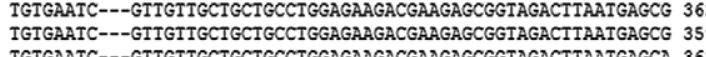

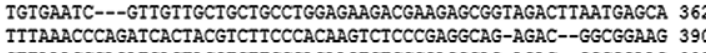

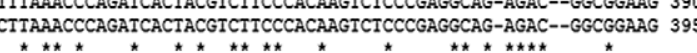

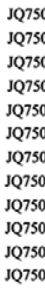

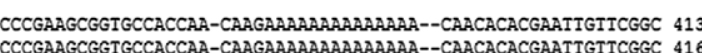

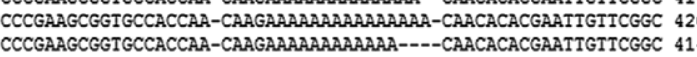

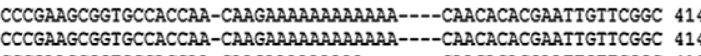

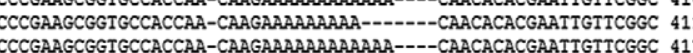

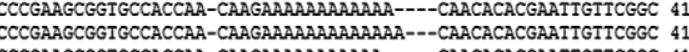

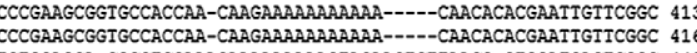

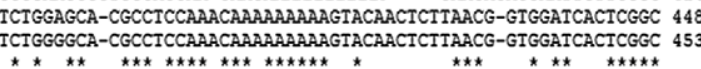

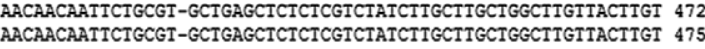

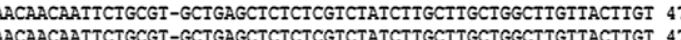

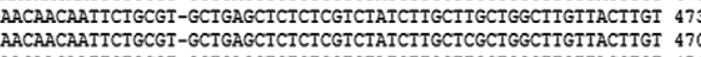

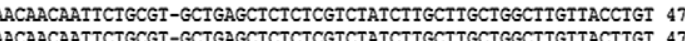

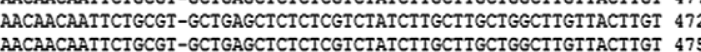

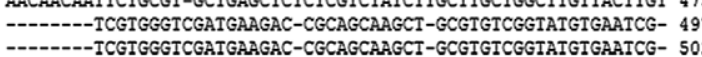

CGTOTAACATTCAGAGGTEAGCGAA----GAAACCCTTTTTGQATA----CCTCT-TA 52

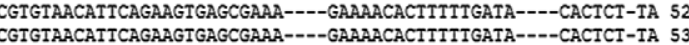

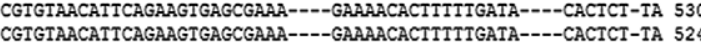

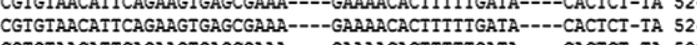

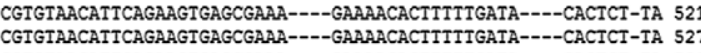
GTGTAACATTCAGAGG GAGCCAAA----GAAACACTTTTTGAA2

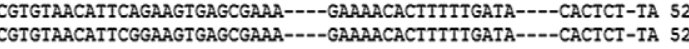

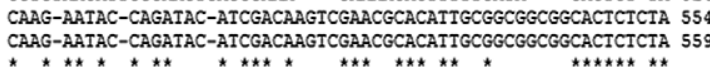

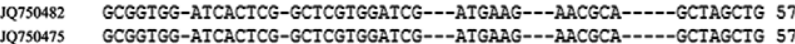

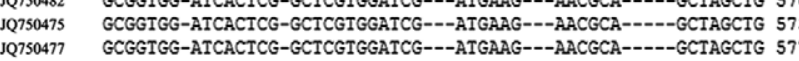

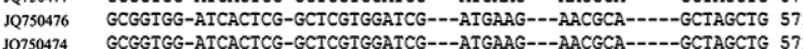

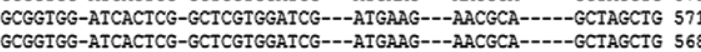

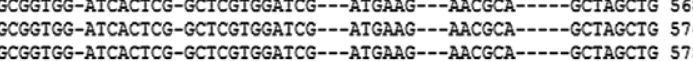

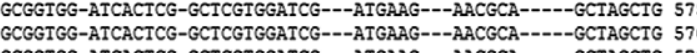

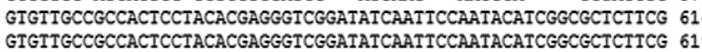

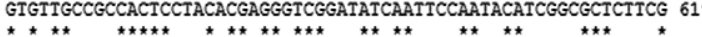

JQ750482 CGATAACTAGTGCGAATTGCAGACACATT----GAGCACA----AAAATIT-CG--AACG 619

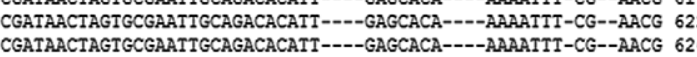

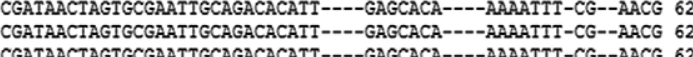

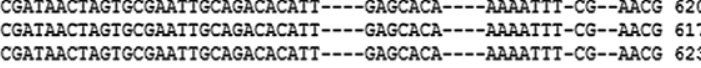

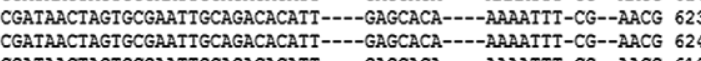

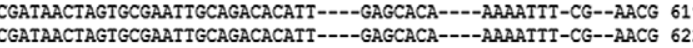

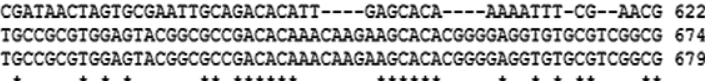

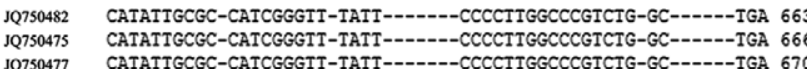

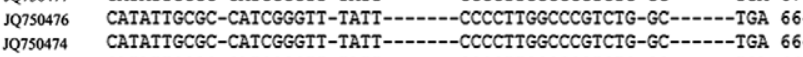

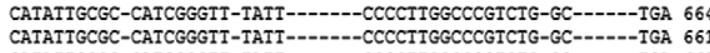

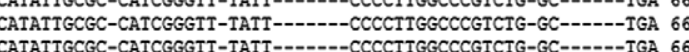

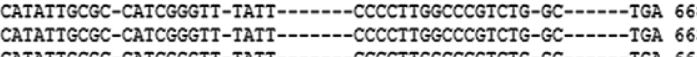

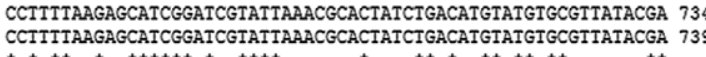

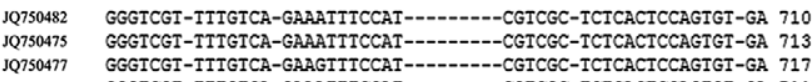
JQ750476 GGT4 GGGTCGT-TTTGTCA-GAAATTICCAT----------CGTCGC-TCTCACTCCAGTGT-GA 71

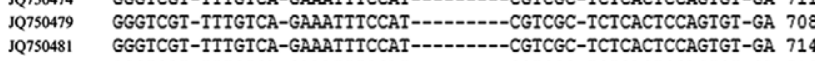

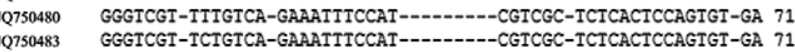

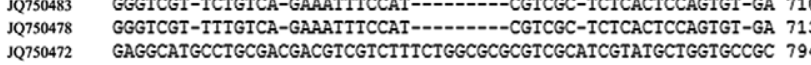

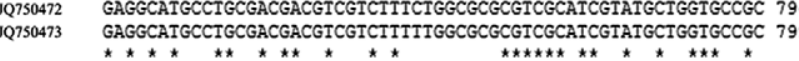

JQ750482 GIGTGTGCGTGTGTGCGCGA------TGAGTGGTCGTCGAGCGATTCCGAATGC--AAGC 762 J075047 GTGTGTGCGTGTGTGCGCGA------TGAGTGGTCGICGAGCGAITCCGAATGC--AAGC,

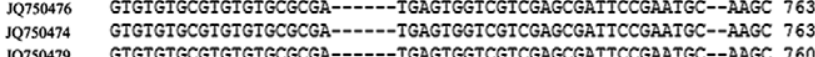
J0750481 GIGIGIGCGIGIGIGCGCGA-------TGAGTGGTGGTCGAGCGAITCCGAATGC--AAGC 76 J0750480

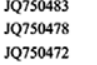

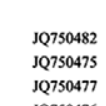

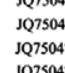

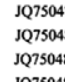

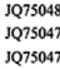

Jersont

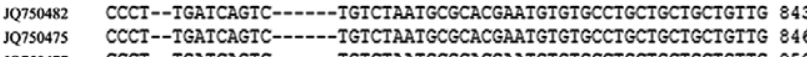

1 12730077

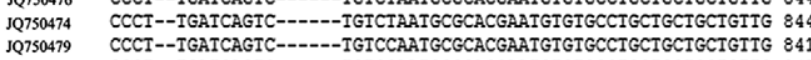

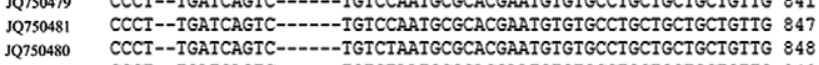

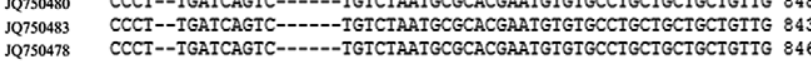

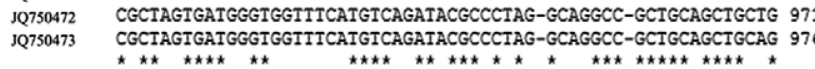

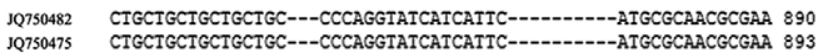

Jersoats

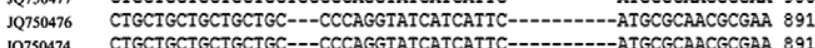

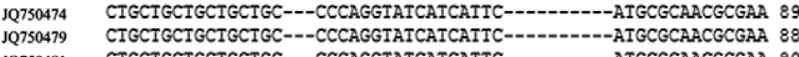

Jersosi
Jorsos

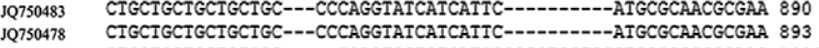

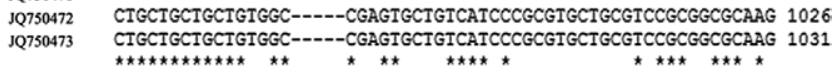

J0750882 CCGT-----CCT--TCCATGTGCTGAT-GCAC------GCCGATGTTCGCACACGCACGT 936

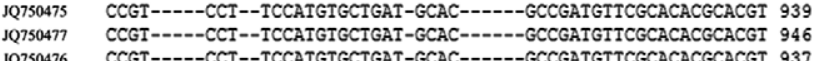

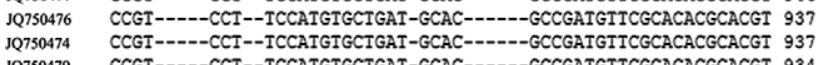

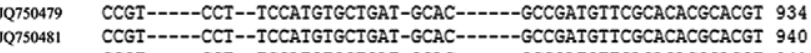

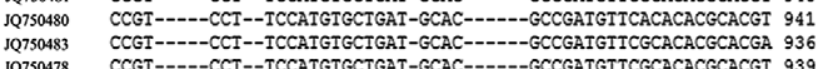

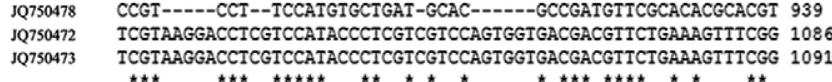

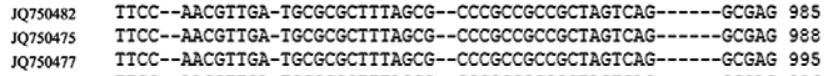

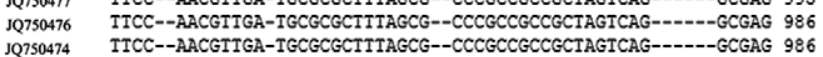

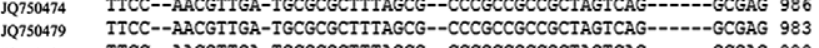

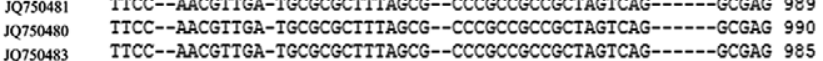

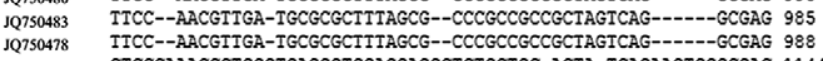

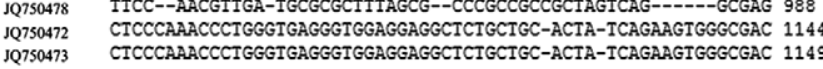

J0750482 CGTGT--GCATACTTGGAGCAGTGCGTGTGAGCAGAA------GACGCAGCATCGACTCT 1037

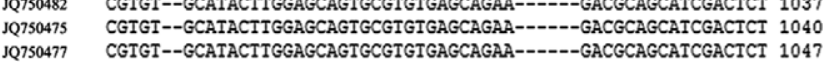

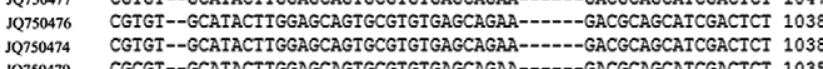

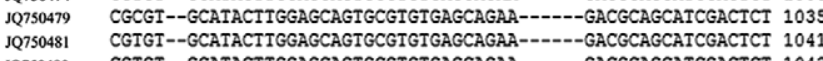

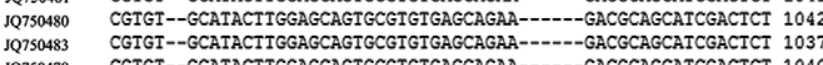

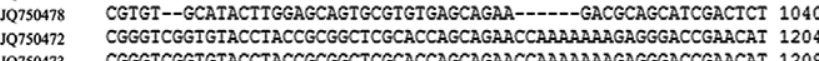

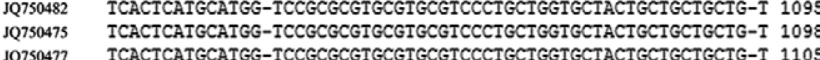

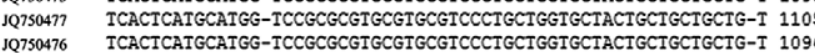

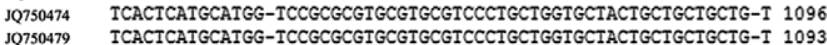

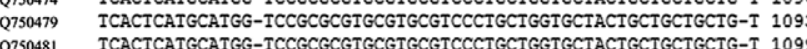

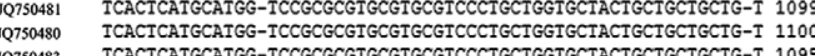

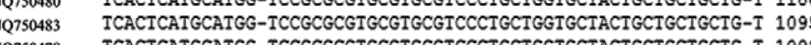

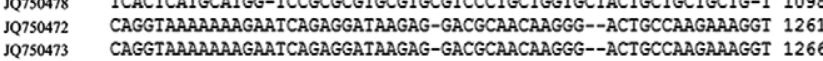

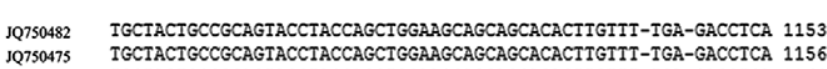

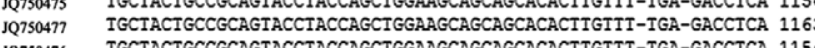

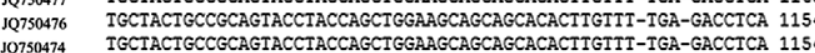

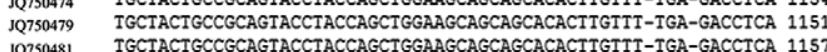

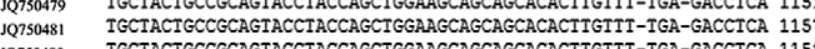

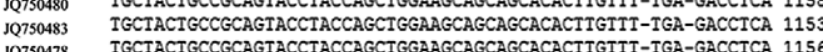

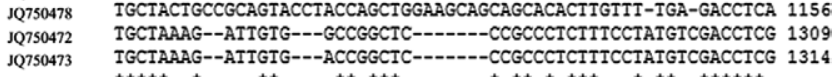

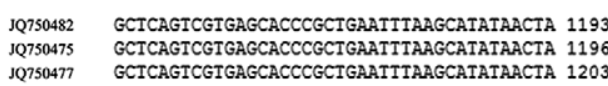

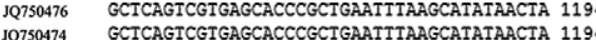

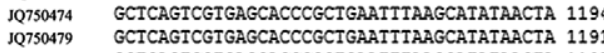

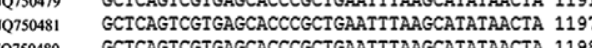

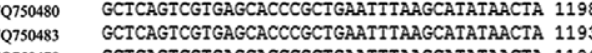

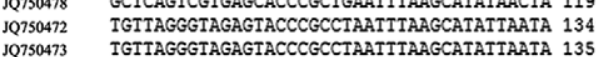

